\title{
(De)stabilizing Self-Identities in Professional Work
}

\section{Anders Buch'}

PhD, Associate Professor, Department of Learning and Philosophy, Aalborg University

Copenhagen

\section{Vibeke Andersen}

Associate Professor, Department of Learning and Philosophy, Aalborg University Copenhagen

\begin{abstract}
It is characteristic of much professional work that it is performed in ambiguous contexts. Thus, uncertainty, unpredictability, indeterminacy, and recurrent organizational transformations are an integral part of modern work for, e.g., engineers, lawyers, business consultants, and other professionals. Although key performance indicators and other knowledge management systems are used to set standards of excellence for professionals, the character of professional work is still flexible, open to interpretation and heterarchical. The very successfulness (or unsuccessfulness) of the work is established in a complex work context where various goals, interests, and perspectives are mediated, altered, contested, mangled, and negotiated in a process of sense-making. The work context is heterogeneously populated by various actors (e.g., the customer, the manager, the colleagues) and actants (e.g., quality systems and technical equipment) that give "voice" to (conflicting) interpretations of what constitutes successful work. Thus, the professionals must navigate in a very complex environment where the locus of governance is far from stable.

These characteristics of professional work seem to have implications for the way professionals make sense of their work and their own identities. The identity work of professionals is interwoven with their professional training and career background. With an academic training and a professional career, the individual typically identifies with the profession's values and adopts a certain way of seeing and approaching the world. This professional outlook typically will constitute the basis of the individual's appraisal of the work and lay out a horizon of expectations in relation to fulfillment, self-realization, and job satisfaction. In this way, the construction of self-identity becomes the yardstick for the individual's sense-making and, a fortiori, for the individual's sense of meaningful work.

In this paper, we will claim that the ambiguity involved in professional work becomes a potential strain on the identity construction of the employees engaged in professional work and a potential source of enthusiasm and self-fulfillment. On a conceptual basis, the paper develops three interpretative frameworks that are useful in understanding how professionals deal with ambiguity in professional work. To illustrate this point, the paper refers to qualitative material from a research project conducted in six Danish knowledge-intensive firms. Referring to this empirical material, we discuss how professionals perceive and relate to their work and the role played by professionalism in this relation. Drawing on neo-institutional theory our paper discusses how professionals draw on different frameworks of meaning in order to stabilize their identities.
\end{abstract}

\section{KEY WORDS}

Neo-institutional theory / Professionalism / Self-identity

\footnotetext{
${ }_{1}$ E-mail: buch@learning.aau.dk
} 


\section{Introduction}

$\mathrm{t}$ is beyond doubt that we have witnessed an intensive process of professionalization in most Western countries. A growing number of people have undergone higher education, obtained university degrees, and joined the ranks of professionals. However, the picture is not that clear when we investigate how professional work has developed in relation to its characteristics and status. As the socioeconomic, organizational, and cultural frameworks have changed, so has professional work (Friedson 1986). In addition, the picture becomes even more complex if we take into consideration how professionals reflect upon their own practices and their professionalism (Hjort 2004). While a growing number of people have obtained university degrees and practice as, e.g., physicians, engineers, and lawyers, some researchers claim that professional work has in fact been de-professionalized and even proletarianized (Leicht \& Fennell 2001). Likewise, studies of contemporary professional work point to the fact that professional work increasingly is subsumed and governed by new principles and technologies of management that delimit professional autonomy (Broadbent et al. 1997; Dent \& Whitehead 2002). In addition, we can observe that while professional expertise is in great demand from decision makers, citizens, consumers, and industry, the authority and status of experts and professionals are contested and problematized (Collins \& Evans 2007; Gibbons et al. 1994; Nowotny et al. 2001). It is thus characteristic of much professional work that it is performed in ambiguous contexts. Uncertainty, unpredictability, indeterminacy, and recurrent organizational transformations are an integral part of modern work for, e.g., engineers, lawyers, business consultants, and other professionals (Alvesson 2004). Although key performance indicators and other knowledge management systems are used to set standards of excellence for professionals, the character of professional work is still flexible, open to interpretation, and heterarchical (Broadbent et al. 1997; Starck 2009). The very successfulness (or unsuccessfulness) of the work is established in a complex work context where various goals, interests, and perspectives are mediated, altered, contested, mangled, and negotiated in a process of sense-making (Weick 1995). The work context is heterogeneously populated by various actors (e.g., the customer, the manager, the colleagues) and actants (e.g., quality systems, technical equipment) that give "voice" to (conflicting) interpretations of what constitutes successful work. Thus, the professionals must navigate in a very complex environment where the locus of governance is far from stable. The role of professionalization is thus far from clear-cut.

These elements of contemporary professional work seem to have implications for the way professionals make sense of their work and their own identities. The identity work of professionals is interwoven with their professional training and career background. With an academic training and a professional career, the individual typically identifies with the profession's values and adopts a certain way of seeing and approaching the world. This professional outlook typically will constitute the basis of the individual's appraisal of the work and lay out a horizon of expectations in relation to fulfillment, self-realization, and job satisfaction. In this way, the construction of selfidentity becomes the yardstick for the individual's sense-making and, a fortiori, for the individual's sense of meaningful work.

In this paper, we wish to develop conceptual tools that can be used in discussing professional work in relation to the identity construction of professionals and the meanings ascribed to professionalism and professional work. We will conceptualize how 
professionals perceive and relate to their work and the role played by professionalism in this relation. Our aim is to specify how patterns of professionalism can be used as guiding principles for engaging in work. In a series of qualitative focus group interviews with professionals and their managers in six Danish knowledge-intensive firms, efforts have been made to investigate how the professionals make sense of their work and how they construe their professionalism. For clarity, it should be stressed that the empirical material referred to here will serve as illustrations in our conceptual development of interpretative frameworks of sense-making. We do thus not claim to infer-in any strict inductive or "grounded" sense-the existence of the conceptual frameworks in the argument presented here. We rather suggest an analytic and conceptual framework-inspired by neo-institutional theory-that can encompass the seemingly ambiguous perceptions of the knowledge workers. We will thus use theoretical resources from neo-institutional theory (mainly Scott 2008a, 2008b) to conceptualize three interpretative frameworks that professionals can draw upon in making sense of their day-to-day activities. In contrast to classical functionalist and/or structuralist research in the professions, we are not aiming at setting up criteria of demarcation for professionalism or to inquire if professionals have been de-professionalized, proletarianized, or in other way deprived of their traditional status and positions within societal hierarchies. Our focus is limited to the investigation of how professionals use their profession as an institution within society in their ongoing efforts to construct and reconstruct their (professional) identities. More specifically, we wish to investigate how professionals can use professionalism as a means to stabilize their identities when confronted with work or working conditions that are perceived as straining. Furthermore, we wish to investigate if and how professional orientations can function as a shield under straining conditions or professional attitude on the contrary intensifies strain in these situations.

\section{The ambiguity of professional work}

"You don't always have the feeling that your job is straight to the point. Actually, you can have your doubts: Say, did I get it right this time? If you're working on something that's part of somebody's assignment. You've been given some vague constraints for the solution of the task and you get back with your output. And you don't get any response on your work. You get kind of troubled. That's how I feel and I think: Gee-did I get the perspective on the problem right? For example when I do risk assessments. Such things can be done within 11/2 page. [But] it can easily stretch over 7 pages depending on how thoroughly you deal with the assignment. In situations like this I feel I'm in need of feedbackthat's what I think." (From an interview with Nina-an experienced engineer working in an engineering consultancy firm.)

Nina's remarks remind us that engineering work and performance are susceptible to interpretations. Although professional work can in fact be regulated by the laws of nature, by rigorously audited quality standards, or by strict company procedures, there is still considerable room for personal judgment. This interpretative flexibility and openendedness have been argued strongly by theoretical and empirical studies in science and technology. Bucciarelli and Kuhn (in Barley \& Orr 1997, 213) make the point in relation to engineering design when they write: 
"It is not difficult to lay out performance specifications at the beginning of the design process; indeed, it is standard practice. What is difficult-probably impossible-is retaining those specifications without an ongoing process of modification, clarification, negotiation and joint meaning-making. Specifications that seem clear at the outset are stretched and challenged by the design process itself; ambiguities, incompletenesses, and contradictions are uncovered as part of the process of discovery that is design."

And Karl Weick generalizes and exemplifies the same point when he writes:

\begin{abstract}
"In real-world practice, problems do not present themselves to the practioners as givens. They must be constructed from the materials of problematic situations which are puzzling, troubling, and uncertain. In order to convert a problematic situation to a problem, a practitioner must do a certain kind of work. He must make sense of an uncertain situation that initially makes no sense. When professionals consider what road to build, for example, they deal usually with a complex and ill-defined situation in which geographic, topological, financial, economic, and political issues are all mixed up together. Once they have somehow decided what road to build and go on to consider how best to build it, they may have a problem they can solve by the application of available techniques, but when the road they have built leads unexpectedly to the destruction of a neighborhood, they may find themselves again in a situation of uncertainty." (Weick 1995, 9)
\end{abstract}

Thus, contrary to common-sense perceptions, there are no clear or predetermined standards for what makes engineering work-and other kinds of complex professional work-successful. The very successfulness (or unsuccessfulness) of the work is established in a complex work context, in which various goals, interests, and perspectives are mediated, altered, mangled, and negotiated. The work context is heterogeneously populated by various actors (e.g., the customer, the manager, the colleagues) and actants (e.g., quality systems, technical equipment) that give "voice" to (conflicting) interpretations of what constitutes successful work. Although local routines, standards, and conventions guide the day-to-day work and make "going on" possible, these routines can be interrupted and questioned. The increasing complexity of professional work makes it likely that the work routines are in fact frequently interrupted. Restructurings, organizational changes, new managerial philosophies, and techniques count among the more spectacular interruptions of everyday work routines, but local work routines may also be questioned by colleagues from other departments in the company and colleagues with other professional backgrounds (Lin \& Beyerlein 2008). All in all, professional work is inherently ambiguous. The work is characterized by a high level of ambiguity in input, process, and output. Although professional work can be rooted in well-established bases of professional practice and knowledge (e.g., as in the case of traditional engineering knowledge about "how things work" in the physics and instrumental processes), the work context of professional work is in fact highly unstable and ambiguous and subject to interpretation.

\title{
Professionals' identity work
}

These characteristics of professional work seem to have implications for the way in which professionals make sense of their work and their own identities. In a general 
theory of the psychological makeup of individuals, Giddens (1991) describes how identity work has developed as a social, reflexive, and subjective project in late modernity. Giddens uses the term "self-identity" to describe the individual's ongoing reflective attempts to make sense and coherence of its experiences and to stabilize the self. Normally, the self is stabilized through unproblematic routine actions of the practical consciousness. These routine actions are fundamental to our ability to carry out ordinary social interactions and tasks, and they provide a basic cognitive and emotional platform for the development of the self-the ontological security of our existence. However:

On the other side of what might appear to be quite trivial aspects of day-to-day actions and discourse, chaos lurks. And this chaos is not just disorganisation, but the loss of a sense of the very reality of things and of other persons. (Giddens 1991, 36)

In other words, the individual continuously must engage in a sense-making endeavor in order to secure the ontological security of the identity. The continuous reproduction of the self-identity is needed in order not to lose sense of reality and face existential anxiety. The reflective construction of self-identity is based on social and cultural resourcessuch as language, symbols, meanings, and values. These elements are the fundamental elements of identity work, and with these elements the individual constructs and stabilizes the identity. The identity work of professionals is interwoven with their professional training and career background. With an academic training and a professional career in, e.g., engineering, the individual typically identifies with the profession's values and adopts a certain way of seeing and approaching the world (cf. Goodwin 1994). Weick summarizes how self-identity and the framing of a situation or a perspective correspond:

"Depending on who I am, my definition of what is 'out there' will also change. Whenever I define self, I define 'it,' but to define it is also to define self. Once I know who I am then I know what is out there. But the direction of causality flows just as often from the situation to a definition of self as it does the other way. And this is why the establishment and maintenance of identity is a core preoccupation in sensemaking and why we place it first on our list." (Weick 1995, 20)

Typically, the professional outlook will constitute the basis of the individual's appraisal of the work and lay out a horizon of expectations in relation to fulfillment, self-realization, and job satisfaction (Billet et al. 2006; Ibarra 1999; Schein 1978). In this way, the construction of self-identity becomes the yardstick for the individual's sense-making and, a fortiori, for the individual's sense of strain or enthusiasm in relation to work. Strain can be caused by work-related conflicts, unfulfilled ambitions, and professional intimidations-strains that put pressure on the professional self-identity and threaten the individual's ontological security. For professionals, work will become straining when their expectations and professional aspirations are not met. When the self-identity adopts a professional codex or ethos, it will be straining to experience conflicts that intimidate or sidestep the values of the profession. It will be difficult for the professional identity to make sense of these violations. They will be perceived not only as unreasonable actions but also as a personal assault, degrading or senseless. The inherent ambiguity of the work is a constant challenge for sense-making and the maintenance of self-identity. 


\section{Strain and enthusiasm in professional work-repots from six knowledge-intensive Danish firms}

The ambiguity involved in professional work becomes a potential strain on the identity construction of the employees engaged in professional work and a potential source of enthusiasm and self-fulfillment. Due to the incessant discussion and negotiation of their performances and roles, the professionals are constantly faced with doubts and insecurities about the relevance, use, and meaning of their work; yet, these negotiations also hold the prospect of receiving acknowledgment of their importance in developing and executing special assignments. The professionals constantly have to reflect on their contribution to and their entitlement in the organizations, in society in general, and not least in relation to personal expectations to career development and work life. The nature of their work requires them continuously (and often openly) to define and substantiate themselves. This makes their work a field of intense and ongoing identity construction and development (Alvesson \& Willmott 2002). When the challenges of the job are successfully overcome, feelings of enthusiasm are evoked, but when they are not, the result may lead to anxiety, doubt, confusion, and feelings of guilt and shame. Due to the ambiguous character of professional work, the identity development and construction of the professionals are under pressure (Alvesson 2004).

Although the overall ambition of this paper is conceptual, we refer to empirical findings from a Danish research project to illustrate our arguments. In what follows, we will thus briefly report the findings of the research project without going into details.

In a series of qualitative focus group interviews with professionals and their managers in six Danish knowledge-intensive firms (two engineering consultancy companies, one public administration in a municipality, one trade union for professionals, one advertisement division in a production company, and a newspaper), efforts have been made to map the enthusing and straining elements of professional work. At each company, four focus group interviews were conducted as "workshops" with 6-10 participants. The participants were asked-collectively—to draw a mind map of the straining and enthusing elements of their work. Each workshop was completed in 2-3 hours. In construing the mind map, the participants were asked to explain and discuss why the elements of their work were conceived as either straining or enthusing. ${ }^{1}$ In what follows, we have condensed some of the thematic discussions of the interviews.

One theme of the interviews deals with professionalism:

- The interviews point to the importance of professional development as a prerequisite for the feeling of enthusiasm. The professionals stress that they thrive on opportunities to struggle with challenging assignments that give room to contemplate technical problems. One engineer sees technical contemplation as the "fuel" that keeps him going, and another one expresses his wish for room to do "nerdish" work. It is obvious that the term "nerd" has a very positive meaning among the engineers and is closely associated with the engineering ethos.

- It is also very important for the professionals to be recognized as accomplished and competent professionals by their colleagues, superiors, customers, and fellow professionals.

- The professionals do not take their professionalism for granted. On the contrary, professionalism is a thing that needs to be accomplished and proven on a regular 
basis. The strive toward personal fulfillment and development is tightly interwoven with a strive toward overcoming and solving technically challenging problems.

Another theme in the interviews addresses the need to produce "results" or manifest products:

- Some professionals consider it very important that their work actually adds value to someone or that the work actually results in the fabrication of a concrete (and tangible) product. One engineer tells a story about how proud he was to point to a bridge when driving on the freeway with his son and say: "Dad built that bridge." Others make the point in other words: "I want my work to make a difference [to my fellow citizens]."

- The ambition to make a difference is closely related to the professionals' feeling of pride in their job and the product they produce. It is mandatory that the professionals can vouch for their products and that the quality of what they deliver is impeccable. If the professionals are forced to deliver a service or a product halfdone, they feel bad about the situation and feel that their professionalism is being compromised.

This last point about the quality of the products of their work is further developed in discussions about the fragmentation of their workdays:

- Working on several different assignments during a workday can be very stressful for the professionals. They feel that their working hours become fragmented when they have to attend to many different assignments during the day. They feel the lack of continuity very unsatisfying because it deprives the professionals of contemplating the more technical problems of their work-which eventually results in unacceptable quality standards.

- Even though the problems are solved on an acceptable basis according to the company's quality standards, the professionals often feel that the fragmented workday does not leave room to solve the problems in ways that are acceptable to their own professional standards of quality. In effect, the professionals work longer hours in order to raise the quality level of the products-even though the budgets do not give room for this. Typically, the professionals take the extra time to deliver high quality and omit to invoice the extra time spent.

Finally, the professionals are very concerned with questions about management and feedback:

- The professionals appreciate autonomy in their work. Self-management is the dominant form of management when it comes to giving shape and structure to the assignments and the working days. Allowing the professional judgments and individual preferences to structure work are seen as the most effective and satisfying way to get the job done-both managers and employees agree on this point. However, the professionals often feel that the autonomy comes at a price. They often feel that they are left in a vacuum where they have to make decisions and perform without any clear guidelines. Nina's remarks—quoted earlier-exemplify this point. The professionals 
cry out for feedback-from colleagues, managers, and customers. The ambiguity of professional work calls for feedback to let the professionals know they are on the right track.

In summary, the enthusing elements identified in the interviews in all of the six Danish knowledge-intensive firms concern:

- professionalism

- development prospects-professionally and personally

- delivering the results (achieving results)

- identification, pride, and meaning

- autonomy

- recognition and feedback

- social support from colleagues

- clear framework and "good management"

The themes regarding elements in the work that produce strain decidedly mirror those listed as leading to enthusiasm. Thus, they address the following issues:

- too much work

- too diversified tasks

- interruptions

- not delivering results

- ambiguous demands, vague framework— “bad management”

- unpredictability/insecurity

It is interesting per se to find out what precisely the professionals perceive as, respectively, enthusing and straining elements. However, this is not the ambition of this paper. What is of importance in this context are the complexities and ambivalences in professional work. It appears that elements that enthuse the professionals-professionalism, developing products of high quality, autonomy-are the very same elements that cause strain in the work. This entails that the very elements that feed the employees' sense of enthusiasm in their work and provide them with fuel to go on are the ones that in the end tip them over the edge and become a strain. When the professional ambitions and values are compromised, their enthusiasm translates into strains and frustrations. It is another interesting point that many of the elements that lead to enthusiasm and strain in professional work are produced in the clash between the professionals' subjective ambitions and professional aspirations on the one hand and the objective reality of the organization on the other hand.

\section{Stabilizing frameworks in professional work}

Various resources and frameworks of sense-making are available for the professionals in their efforts to cope with conflicting demands, extreme complexity, and heterogeneity. These frameworks deliver cultural resources, stories, metaphors, and discursive material that can be applied in order for the individual to establish their subject positions within 
the dynamic field of the workplace and substantiate their self-identity. W. Richard Scott, one of the founders of neo-institutional theory, ${ }^{2}$ argues that:

"...the insight that professional authority is based on the ability to create and apply a set of cultural-cognitive, normative and/or regulatory elements that provide frameworks for dealing with various types of uncertainty is at the core of the institutional perspective. [...] In our own time, the professions are the primary societal institutional agents." (Scott 2008a, 227)

In accordance with this institutional perspective, professions can be seen as regimes of competence that give authority and legitimacy to activities, relations, and resources. Scott identifies the elements of institutional hegemony in the rules, norms, and beliefs of the professionals. Institutions-and professional hegemony-are comprised of three pillars (Scott 2008a, 2008b, cf. chap. 3):

- the regulatory pillar, which stresses rule-setting, monitoring, and sanctioning activities, both formal and informal;

- the normative pillar, which introduces a prescriptive, evaluative, and obligatory dimension into social life, stressing "appropriate" behavior-given the demands of the situation and the actor's role within it—versus "instrumental" behavior, in which attention is focused on the actor's preference and pursuit of self-interest; and

- the cultural-cognitive pillar, which emphasizes the centrality of symbolic systems: the use of common schemes, frames, and other shared symbolic representations that guide behavior.

Thus, the three institutional pillars enhance and restrict behavior by enforcing professional standards of compliance. The constitutive elements of the institutional pillars are summarized by Scott in Table 1.

Table I Three institutional pillars (Scott 2008b, 51 ).

\begin{tabular}{llll}
\hline & Regulative & Normative & Cultural-Cognitive \\
\hline Basis of compliance & Expedience & Social obligation & $\begin{array}{l}\text { Taken-for-grantedness/ } \\
\text { shared understanding }\end{array}$ \\
\hline Basis of order & Regulative rules & Binding expectations & Constitutive schema \\
\hline Mechanisms & Coercive & Normative & Mimetic \\
\hline Logic & Instrumentality & Appropriateness & Orthodoxy \\
\hline Indicators & Rules & Certification & $\begin{array}{l}\text { Common beliefs } \\
\text { Shared logics of action } \\
\text { Isomorphism }\end{array}$ \\
\hline Affect & Saws & Accreditation & Certainty/confusion \\
\hline Basis of legitimacy & Fear/guilt/innocence & Shame/honor & Comprehensible \\
& Legally sanctioned & Morally governed & Recognizable \\
& & & Culturally supported \\
\hline
\end{tabular}


Scott's analysis of professional authority establishes a framework that allows us to understand how professionals use institutionally founded discourses, symbolic representations, and routines in order to reduce contingency in their work and thereby stabilize their self-identities. The professionals are engaged in a sense-making endeavor that reflexively substantiates their professional identities by aligning their actions and beliefs with the professional community. The professional identity of the individual is reflected in the historic and sociocultural ethos of the profession. Thus, this professional ethos-the values, standards, and ideals of the professional institution-provides the individual with guiding principles that set criteria for the (un)successfulness of their (professional) achievements. The professional institution provides resources for the production of self-identities and a point of reference in the continuous reproduction of identities. This helps the individuals to substantiate and stabilize their identities. On the other hand, however, identities can come under pressure when individuals are confronted with conflicting regimes of authority. In our studies, we find examples where professionals' identities are confronted with conflicting regimes of authority. We see how engineers employed in engineering consultancy firms are put under considerable pressure when they try to honor the standards of their profession-e.g., rigor and meticulousness of their calculations, and professional accountability to their costumers and peers. The engineers are faced with conflicting demands of efficiency and swiftness. Confronted with corporate demands of economic and bureaucratic accountability, the engineers are often forced to compromise. Thus, they are put in situations where they need to navigate between conflicting regimes of legitimacy. This can indeed be challenging and prompt substantial identity work.

In what follows, we will discuss three frameworks of identity construction in professional work. For short, we will call these frameworks the professional framework, the bureaucratic framework, and the broader framework. These frameworks are constructed through our interpretations of our empirical material. Thus, they reflect the collective narratives of the interviewees, but in an elaborate and condensed way. It goes without saying that the narratives of the interviewees are highly complex and unique. The professionals negotiate their identities in a contingent and situated process of sense-making that is in need of detailed empirical investigation. It is not our ambition to reduce the complexity of these narratives by constructing explanatory models of identity construction as such. The frameworks should rather be viewed as analytic constructions that help us understand the dynamics of identity construction in the context of professionals. We also recognize that identity construction is closely linked to formative categories of ethnicity, gender, and class that are seamlessly interwoven with the frameworks presented here. However, our study has a much more limited focus on the construction of professional identities. We want to stress that the conceptual status of the frameworks is analytic. Thus, the frameworks are not intended as "explanatory devices" or strictly representative categories. The frameworks should be seen as a product of our effort to capture some predominant thematic streams in our interviews on an institutional level. In what follows, we expound these frameworks on a general level using material from our interviews and from relevant literature.

\section{The framework of the profession}

Our interviews illustrate that the professionals draw heavily on a professional framework in their sense-making. An architect working with design says in an interview: 


\begin{abstract}
Architect: "I want to be passionate about my job. And I'm at my best when I'm passionate. It makes me efficient, swift, etc."

Interviewer: "...and you can only feel passion when your professionalism and your skills are in play?"

Architect: "Yes. Maybe you could put it this way: It's also a matter of integrity. That is, the stuff I produce should be as good as it can get. Not just because I think so, but because I've put some consideration into the matter. And if you can't argue against it, but just say: It shouldn't be like that! Well, then it's right. If not, I might as well not bother."
\end{abstract}

The educational background as an architect, engineer, biologist, lawyer, etc. and the socialization that goes along with the study give the professional a specific perspective on "reality." Scott points out that the cognitive-cultural pillar regulates the actions of the professionals by structuring their ideas and perceptions. For example, medical doctors are in consensus about what constitutes clinical work and how doctors should behave in relation to their patients (Scott \& Backman 1990). Knorr Cetina (1999) describes how professionals live in epistemic cultures that help them create and validate knowledge. The culture of the professionals specifies (although often tacitly) their basic presumptions about reality; the culture supplies the professionals with a language, concepts, and root metaphors (Lakoff \& Johnson 1980, 1999) that enable them to make specific and subtle distinctions; the culture specifies how problems should be framed and solved and what constitutes problems; it specifies principles for valid reasoning. Thus, the professional culture defines the content and the methods of the professional work.

For instance, a distinct epistemic culture exists in engineering. Engineers share a common cosmology. Bucciarelli (1994) has described this cosmology as an "object world." The object world is a domain of thoughts, actions, and values that guide the work of the engineers and their way of seeing the world. In the cosmology of the object world, precision, decidability, rigor, unambiguousness, consistency, usefulness, determinism, rationality, mechanistic models, reductionism, value-freedom, results, and achievements are all held in high esteem (see, e.g., Kunda 2006; Layton 1986; Williams 2003). Many of these ideals are inherited from the scientific worldview. The values are reproduced through basic education in engineering that stresses scientific methods and disciplines. The engineering ethos promotes scientific methods and principles that reduce complexity in unambiguous models.

Bucchiarelli and others have effectively shown that, although these schemas, ideas, and standards are held in high esteem by the engineers themselves, they do in no way reflect engineering work as performed in real life. Engineering is immersed in social processes that do not live up to ideals of the object world. Ambiguity and social interests are part and parcel of engineering practice. Thus, a discrepancy exists between the espoused (idealized) cosmologies of the engineers and the actual principles that guide their dayto-day practice. The espoused framework is in a way archaic: it reflects a vision of engineering inherited from old ideals about the engineering profession that is in fact at odds with present-day engineering practice. The archaic professional framework, however, can give comfort and stability in the turbulent world of ambiguities. Belonging to a profession provides an opportunity to enter a frame of reference in which it is possible to understand oneself and one's work in terms of a number of conceptual schemas, codes, and concepts of values. Life within the object world guards against ambivalence and 
anxiety. In this way, the profession — understood broadly as a particular "mindset," internalized for instance through long university educations-may act as a critical reference point to the engineers, making it possible to keep informed and find one's bearings in the complexity, especially when the identity is under pressure. At the same time, however, it is clear that this identification, emphasizing the cultural and cognitive standards of the engineering profession, may fall short when it encounters the aims and frameworks of the work that exist in the organization. The archaic "mindset" of the engineering culture can turn out to be an absolute impediment. Far from dealing with the ambiguities involved in engineering work, clinging to the archaic professional framework is close to a state of denial: the troublesome complexity of the work is shunned and seen instead in terms of the object world. This state of denial is of course counterproductive in the long term. The archaic professional framework of sense-making within engineering culture shows when large numbers of engineers voice their concerns about the restricting nature of their jobs. They view themselves as "atypical" engineers, because they are not doing "engineering in its proper sense" (Buch 2002; Christensen \& Buch 1999; Parker 2004). This tendency to project idealized and archaic conceptions of engineering work as standards for their professional identities doubles the ambiguity of their situation. In the first place, the heterogeneous character of their work does not provide fixed criteria or standards to direct actions. Second, the archaic professional self-image offers idealized standards that cannot be met in the quotidian lives of the engineers. Thus, in the case of engineers, adopting the professional framework as a sense-making framework may alleviate anxiety and strain, but in fact it can also be counterproductive: upholding strict professional engineering standards in a highly complex and heterogeneous work environment may put considerable strain on the self-identity.

\section{The framework of bureaucracy}

Professional work is commonly conceptualized as creative, dynamic, and innovative. The complexity of professional work and the demand for esoteric expertise do not easily allow for standardization and routines. Thus, professional work is often set in harsh contrast to bureaucratic work. Kärreman et al. $(2002,73)$ describe this widely held perception in Table 2.

Table 2 Knowledge-intensive firms and the bureaucratic ideal type: A comparison (Kärreman et al. 2002, 73).

\begin{tabular}{lll}
\hline Key aspects & Bureaucratic ideal type & Knowledge-intensive firm \\
\hline Mode of production & Standardization & Ad hoc problem solving \\
\hline Dominant control logic & Enforcement of rules & Negotiated order \\
\hline $\begin{array}{l}\text { Environmental contingencies } \\
\text { providing relative advantage }\end{array}$ & Stable, anticipated change & Turbulent, disruptive change \\
\hline Nature of product and services & Homogenous & \\
\hline Leveraging capital & Financial & Ambiguous \\
\hline Locus of power & Manager & Intellectual \\
\hline
\end{tabular}


It is correct that professional work is known by its high complexity, but nevertheless, the degree of complexity in professional work has variations. Davenport (2005) makes this point. Professional work spans from highly complex and experientially based work that requires expert judgments and (tacit) knowledge (e.g., primary care physicians) to more systematic and repetitive work that relies on formal processes, scripts, methodologies, and explicit standards (e.g., engineers working with computer codes). Thus, Davenport does not see bureaucracy as antithetical to professional work. Bureaucracy should rather be seen as an integral element in professional work that may have more or less weight in guiding work. Kärreman et al. connect with this observation. Their studies of work processes in knowledge-intensive firms in the biomedical industry and in consultancy show that work, decision-making, and collaboration are highly regulated through rules, scripts, and bureaucratic procedures. Thus, bureaucracy is not antithetical to professional work. In fact, Kärreman et al. document that bureaucratic procedures can play a dominant role in structuring professional work. But how does bureaucratization of work affect the professionals? Does bureaucracy inhibit the professionals and inflict strain? It would seem so. In a conventional perspective, professional work is seen as autonomous-entirely regulated by cognitive, moral, and cultural standards prevalent in the profession. Thus, bureaucratic regulations are likely to be classified as straining. Our interviews show that many professionals share this view. They describe bureaucracy as expedient, imposed on their work as a foreign element, counterproductive, and something that is likely to obstruct their work. They associate bureaucracy with situations in which their expertise is overruled by arbitrary rules and criteria. In these situations, their professional status and integrity are offended and their professional identities are under siege.

This line of reasoning is echoed in many observations (e.g., Broadbent et al. 1997) and it runs as a theme in our interviews. It can be illustrated through a statement made by a professional employed as a civil servant. She prepares the agendas and proposals for the board of a Danish municipality:

"And there you are. You have put all your efforts in preparing the proposal and it is ready just in time. Finishing the proposal would normally take one week of preparations-but you have done it in just one day-and night! And you can answer for this proposal in all respects. Then they just mention that some commas are missing. This really frustrates you!"

This frustration is a result of the lack of appreciation of her work. Her work is not assessed on professional terms, but judged in accordance with an arbitrary and insignificant standard (comma faults). These formal standards of spelling do not bear significantly on the professional system of legitimacy and thus are seen as irrelevant markers for doing a good job.

Professionals have a tendency to demonize bureaucracy. However, bureaucracy in professional work is not entirely negative, although it is often portrayed in this way. Kärreman et al. $(2002,79)$ point out that bureaucracy may in fact alleviate strain and stabilize professional identities by supplying standards in ambiguous work:

"The bureaucratic modes of operation at Beta are, of course, always present, even in team interaction. However, they operate more as a supporting structure than as a controlling and regulating structure. Bureaucratic procedure appears to be more like a vehicle of shared 
understanding than a protocol for prescribed behaviour. In this sense, bureaucracy at Beta appears to be a cultural phenomenon: an expression of a particular collective mindset and frame of reference."

Thus, bureaucracy can be seen as a mode of governance that helps to handle complexity and ambiguity at work. Bureaucracy in professional work cannot eliminate ambiguity entirely—if it did, it would hardly qualify as professional work any longer. But a selective bureaucratization of professional work may provide guidelines and standards. Bureaucracy can provide a common frame of reference for the professionals by establishing a repertoire of procedures that can either "take over" negotiations and structure collaboration and interaction or function as enabling material that may bring closure to ongoing negotiationsthus reducing complexity. In this sense, bureaucracy can be seen as a standardization and "short hand" for more tedious, repetitive local negotiations of competence.

To obtain this positive effect, it is crucial that the selective bureaucratization of work does not violate or in any way get in conflict with the cognitive and cultural codex of the professionals. Bureaucracy is felt straining if it invades certain domains of work and certain areas of professional expertise and judgment. On the other hand, bureaucracy is embraced by the professionals if it does not compromise their professionalism. Adler and Borys (1996) make a distinction between affording and restraining bureaucracies. However, they construe this distinction in a functionalist way, in which affording bureaucracies are defined as procedures that help the professionals to meet the needs of their clients, and controlling bureaucracies are understood as systems of control introduced as a substitute for professional commitment. When we discuss the potential tension between professionalism and bureaucracy, we try to understand this tension in relation to the professionals' continuous project of identity construction. The introduction of new bureaucratic regulations of work is perceived as affording or controlling-as enthusing or straining-according to the professionals' subjective and inter-subjective interpretations of professionalism and their position in the work process. Thus, it is not possible a priori to establish a demarcation between affording and controlling bureaucracies.

\section{Broader frameworks of sense-making}

It is not surprising that professionalism plays a central role in the identity production of the professionals. Similarly, it is no surprise that local regulations of work have an impact on the professionals' feelings of enthusiasm and strain. The institutional conditions and systems of legitimacy in professional work are closely related to the professional ethos and to the local and situated regulations of work in the company. However, the sense-making process is not confined to the professional ethos and the local regulation of work alone. Broader normative institutional formations of social obligation and moral duty are also active. The professionals' sense-making reflections thus appeal to values and ideals that are widely accepted within our society. This is reflected in an interview with a lawyer employed in a trade union:

\footnotetext{
"What makes this job worthwhile and motivating is to help people that are totally...well, people who were given the sack. Their situation is distressful when they get in contact with us, and then a few minutes later...we have created a new reality! And this is a tremendous
} 
satisfaction. You make change. [...] You really feel that you make a difference. In this way the job is very satisfying."

The professionals frequently refer to the effects and consequences of their work. They attach much importance to the fact that their work "makes a difference to someone" or that their work "contributes to (lasting) results." The quoted lawyer makes it clear that he takes a lot of (professional) pride in helping people manage their difficult situations. Thus, the fact that his efforts are appreciated by the union members he helps contributes significantly in his sense-making endeavor. In our interviews, we heard many engineers, biologists, and geologists refer to sustainability: they described their work as environmental work. They have adopted the widespread normative discourse of sustainability to legitimize and substantiate work as meaningful.

A similar, though in part different, strategy of normative legitimization is found in engineers who take pride in their achievements. Thus, an engineer tells us that he took great pride in telling his son that he had built a major bridge that connects islands in Denmark. The bridge comes to symbolize manifestly an undisputable "result" thatdue to its sheer physical presence and materiality-legitimizes the work. This normative legitimization holds_of course - an implicit premise that a bridge is useful to many people, but the corporeal element of the "result" also helps the professional to make sense of his abstract and intangible work. The functionality and lasting character of the bridge ("it will be there when I'm gone") becomes a proof of successful work.

A third-and yet again slightly different-example of normative legitimization of work is found when interviewees stress the importance of achieving economic results. Professionals in engineering consultancy firms or in advertising are enthused by securing an order or in other ways boosting the economic results of the company. They take pride in being a member of "a winning team." These examples show that the professionals' sense-making activities find resources in normative frameworks that transcend the strict professional or bureaucratic systems of legitimacy. Resources from broader moral, social, or political frameworks (e.g., social responsibility and sustainability) are evoked as guiding principles in the sense-making processes along with resources from the professional and bureaucratic framework.

\section{Conclusion}

Professionals draw on different frameworks in their identity work and sense-making endeavors. Following Scott's institutional analysis of professions, these frameworks are identified as a cognitive-cultural framework of professionalism, a regulative framework of bureaucratic rules and procedures, and a normative framework regulated by moral values and ideals rooted in broader societal contexts. Adhering to these frameworks of sense-making can potentially stabilize the self-identities of professionals. The frameworks provide opportunities for ambiguity reduction: the frameworks can provide structure, security, and certainty in the complexities of professional work.

However, the frameworks may also jeopardize sense-making processes. The certainty provided by the professional framework can easily be transformed into professional dogmatism, bureaucracies can produce alienation and inhibition, and blind adherence to normative ideals can result in fanaticism. It is convenient to evoke explicit bureaucratic 
standards in order to justify your work efforts (Kärreman et al. 2002), and you can also find reassurance in professional standards. But the comfort of complexity reduction afforded by the frameworks comes at a price: the professionals can easily end up in a mental cage of professionalism, an iron cage of bureaucracy, or an ideological cage. The frameworks are effective vehicles of complexity reduction and sense-making, but are at the same time potential sources of strain infliction when the professionals are faced with demands of flexibility and change. If the frameworks cannot accommodate these demands, it might result in feelings of identity loss, insecurity, and anxiety.

The interviews in the workshops showed that "professionalism," "recognition and feedback," "clear framework and good management," and "autonomy" were of fundamental importance to the professionals, and that they considered "ambiguous demands, vague framework" - "bad management" and "unpredictability/insecurity" as straining elements of work. In making sense of their work, the participants interpreted actions, events, and situations by mobilizing language, symbols, metaphors, meanings, and values from the frameworks. The frameworks present themselves as resources for the professionals' identity work that can be used in order to meet new challenges and changes in professional work. It is, however, quite another question if these resources are sufficient to meet the demands of contemporary professional work and alleviate strain.

Scott argues that the professions have undergone major endogenous and exogenous changes in resent time. The explosive growth of knowledge in post-industrial society has resulted in greater divisions of labor within professional work. A dual process has thus characterized the development. On the one hand, professional work and knowledge have increasingly become more specialized and esoteric, and consequentially a fragmentation of interests in sub-domains has occurred. On the other hand, an expansion of hyphenated professionals that work to cross disciplinary boundaries has emerged. Furthermore, the increase in knowledge has given rise to commodification, mechanization, and routinization of sub-domains of knowledge and professional work. Professional work has also been exposed to major societal changes. Increasingly, professional work-even scientific research and technical expertise-is validated by logics and criteria of success determined by the market (Gibbons et al. 1994; Nowotny et al. 2001) and still more professionals find employment in large-scale organizations governed by bureaucratic procedures (Kärreman et al. 2002). These major changes in professional work challenge the identity construction of professionals by introducing a diversity of potentially conflicting criteria for "what counts" as standards for professionalism. The cognitive ecologies that facilitate the work of reflective cognition of the professionals have been inflicted with pluralities of endogenous and exogenous points of orientation. The authority of the resources found in the frameworks is being relativized and made conditional on individual orientations, career choices, and local regimes of accountability. Boltanski and Chiapello (2005) and Starck (2009) have pointed at the consequences of the emergence of heterarchical forms in modern work, as regimes of flexibility, that give new meaning to the problems of "self-management." Starck frames the problem involved in heterarchical forms of accountability:

"The problem is that lateral accountability is emotionally demanding. The absence of clear-cut lines of vertical authority involves trade-offs-for you are now accountable to many. And because you are also accountable in many crosscutting, even conflicting registers, you are ultimately accountable to yourself." 
The endogenous and exogenous changes that have affected professional work thus fundamentally alter the basis of authority of professionalism. It is no longer possible for professionals unproblematically to confide in the standards of the profession, to be accountable to corporate procedures, or to adhere to wider societal values. The resources of the frameworks are not fixed to one system of interpretation, but can be made available to multiple systems, and the resources of the frameworks can be used selectively-depending on local and specific strategies of action. Thus, individual professionals cannot mobilize the frameworks in order to alleviate strain. The effectiveness of the frameworks is highly dependent on the collective sensemaking processes and local work processes among the professionals. To alleviate strain in professional work, it is thus necessary to develop collective and local standards of accountability that hold authority in the situated practices of professional work.

\section{Acknowledgement}

The article is based on the research project: "Knowledge Work and Stress - between Enthusiasm and Strain", supported by The Working Environment Research Fund. The authors conducted the research in collaboration with Associate Professor Ole Henning Sørensen and Associate Professor Christine Ipsen.

\section{References}

Adler, P. \& Borys, B. (1996): Two types of bureaucracy: enabling and coercive, Administrative Science Quarterly, 41, 61-89.

Alvesson, M. (2004): Knowledge Work and Knowledge Intensive Firms, Oxford, Oxford University Press.

Alvesson, M. \& Willmott, H. (2002): Identity regulation as organizational control producing the appropriate individual, Journal of Management Studies, 39(5), 619-644.

Billet, S., Fenwick, T., \& Summerville, M. (2006) (eds.): Work, Subjectivity and Learning, Dordrecht, Springer.

Boltanski, L. \& Chiapello, E. (2005): The New Spirit of Capitalism, London, Verso.

Broadbent, J., Dietrich, M. \& Roberts, J. (eds.) (1997): The End of the Professions? The Restructuring of Professional Work, London, Routledge.

Bucciarelli, L. (1994): Designing Engineers, Boston, MIT Press.

Bucciarelli, L. \& Kuhn, S. (1997): Engineering Education and Engineering Practice: Improving the Fit, in Barley, S. \& Orr, J. (eds.): Between Craft and Science. Technical Work in U.S. Settings, 210-229, Ithaca, Cornell University Press.

Buch, A. (2002): Social Theory of Learning, Frederiksberg, Roskilde Universitetsforlag (In Danish).

Buch, A., Andersen, V. \& Sørensen, O. (2009): Knowledge Work and Stress-Between Strain and Enthusiasm, København, Jurist- og Økonomforbundets Forlag. (In Danish).

Christensen, T. \& Buch, A. (eds.) (1999): Engineering Lives-Eight Tales, København, Ingeniørforbundet i Danmark (In Danish).

Collins, H. \& Evans, R. (2007): Rethinking Expertise, Chicago, Chicago University Press.

Davenport, T. (2005): Thinking for a Living. How to Get Better Performance and Results from Knowledge Workers, Boston, Harvard Business School Press. 
Dent, M. \& Whitehead, S. (eds.) (2002): Managing Professional Identities. Knowledge, Performativity and the "New" Professional, London, Routledge.

Friedson, E. (1986): Professional Powers: A Study of the Institutionalization of Formal Knowledge, Chicago, Chicago University Press.

Gibbons, M., Limoges, C., Nowotny, H. \& Schwartzman, S. (1994): The New Production of Knowledge: The Dynamics of Science and Research in Contemporary Societies, London, Sage.

Giddens, A. (1991): Modernity and Self-Identity. Self and Society in the Late Modern Age, Stanford, Stanford University Press.

Goodwin, C. (1994): Professional Vision, American Anthropologist, 96(3), 606-633.

Greenwood, R., Oliver, C., Suddaby, R. \& Sahlin-Andersson, K. (eds.) (2008): The SAGE Handbook of Organizational Institutionalism, London, Sage.

Hjort, K. (2004) (ed.): Professionals—Research in Professions and Professional, Frederiksberg, Roskilde Universitetsforlag (in Danish).

Ibarra, H. (1999): Provisional selves: Experimenting with image and identity in professional adaptation, Administrative Science Quarterly 44(4): 764-791.

Ipsen, C. \& Andersen, V. (2013): A Multi-level, Collaborative and Participatory Model for Prevention of Work-Related Stress in Knowledge Work, Chapter 8 in [Working title] Greg Jenny and Georg Bauer (eds.): Concepts of Salutogenic Organizations and Change: The Logics Behind Organizational Health Intervention Research, Dordrecht, Springer Verlag. Estimated.

Ipsen, C., Jensen, P. \& Andersen V. (2010): Prevention of Work-Related Stress in Practice-A Participatory Approach, in P. Vink \& J. Kantola (eds.): Advances in Occupation, Social, and Organizational Ergonomics (pp. 305-315), Roca Rathon, CRC Press, Taylor \& Francis Group.

Kärreman, D., Sveningsson, S. \& Alvesson, M. (2002): The return of the machine bureaucracy? Management control in the work settings of professionals International Studies of Management \& Organizations, 32(2), 70-92.

Knorr Cetina, K. (1999): Epistemic Cultures. How the Sciences Make Knowledge, Boston, MA, Harvard University Press.

Kunda, G. (2006): Engineering Culture: Control and Commitment in High-Tech Corporations, 2 d edition, Philadelphia, Temple University Press.

Lakoff, G. \& Johnson, M. (1980): Metaphors We Live By, Chicago, University of Chicago Press.

Lakoff, G. \& Johnson, M. (1999): Philosophy in the Flesh, New York, NY, Basic Books.

Layton, E. (1986): The Revolt of the Engineers. Social Responsibility and the American Engineering Profession, Baltimore, The Johns Hopkins University Press.

Leicht, K. \& Fennell, M. (2001): Professional Work. A Sociological Approach, Oxford, Blackwell Publishers.

Lin, Y. \& Beyerlein, M. (2008): Communities of Practice: A Critical Perspective on Collaboration, in Beyerlein, M., Beyerlein, S., Kennedy, F. (eds.): Innovation through Collaboration (Advances in Interdisciplinary Studies of Work Teams, Volume 12), 53-80, San Diego, Emerald Group Publishing.

Nowotny, H., et al. (2001): Re-Thinking Science. Knowledge and the Public in an Age of Uncertainty, Cambridge, Polity.

Parker, L. (2004): The Education and Employment of Engineering Graduates, National Science Foundation, Available online at: http://www.nspe.org/resources/pdfs/blog/AbtReport-on-Engineering-Profession1.pdf.

Schein, E. (1978): Career Dynamics. Matching Individual and Organizational Needs. Reading, MA: Addison-Wesley. 
Scott, R. (2008a): Lords of the Dance: Professionals as Institutional Agents, Organization Studies, 29(02), 219-238, London, Sage Publications.

Scott, R. (2008b): Institutions and organizations, $3^{\text {rd }}$ [1995] edition, London, Sage Publications.

Scott, R. \& Backman, E. (1990): Institutional Theory and the Medical Care Sector, in Cummings, L. \& Straw, B. (eds.): Innovations in Health Care Delivery: Insights for Organization Theory, Greenwich, CT, JAI.

Starck, D. (2009): The Sense of Dissonance. Accounts of Worth in Economic Life, Princeton, Princeton University Press.

Sørensen, O. H. \& Holman, D. (2010). Job-Redesign in Knowledge Work, in P. Vink \& J. Kantola (eds.), Advances in Occupation, Social, and Organizational Ergonomics, 111-120, CRC Press, Taylor \& Francis Group.

Weick, K. (1995): Sensemaking in Organizations, London, Sage Publications.

Williams, R. (2003): Retooling. A Historian Confronts Technological Change, Boston, MIT Press.

\section{End notes}

1 A description of the method used to facilitate and interpret the mind map processes is given in Buch et al. (2009, 147 ff). See also Sørensen and Holman (2010), Ipsen et al. (2010), and Ipsen and Andersen (2013).

2 Neo-institutional theories in the social sciences share a fundamental relational perspective on human action that goes back to the works of John Dewey and Thorstein Veblen. In the contemporary versions of neo-institutionalism, the perspective stresses that organizations are comprised of complex interactions that are in need of legitimacy. Prominent scholars within the neo-institutional tradition include among others James March, Johan Olsen, Walter Powell, Paul DiMaggio, John Meyer, and Richard Scott. For a broad coverage of the thematic discussions within neo-institutionalism, confer with Greenwood et al. (2008). 